\title{
Analysis of a radiographic parameter K-line tilt following adjacent two-level anterior cervical discectomy and fusion: a retrospective study
}

\author{
Zhibin Lan' ${ }^{1}$ Zhiqiang $\mathrm{Wu}^{2}$, Weihong $\mathrm{Xu}^{3}$ and Yuming Huang ${ }^{4^{*}}$
}

\begin{abstract}
Background: T15, C2-7 lordosis, and C2-7 sagittal vertical axis (SVA) are the three most important sagittal parameters in the cervical spine. This study was conducted to investigate the relationships between classical sagittal alignment parameters and a new parameter, K-line tilt, and to study the impact of K-line tilt.

Material and methods: A total of 72 patients who underwent adjacent two-level anterior cervical discectomy and fusion (ACDF) were retrospectively analyzed. Radiographic measurements included T1 slope (T1s), C2-7 lordosis, segment angle (SA), C2-7 SVA, and K-line tilt. The Neck Disability Index (NDI) scores were used to evaluate the clinical prognosis. Pearson correlation coefficients were calculated between radiographic measures. Linear regression analysis was used to analyze the relationship between follow-up K-line tilt and NDI.

Results: $\Delta \mathrm{NDI}$ was positively correlated with $\Delta \mathrm{T} 1 \mathrm{~s}(r=0.620, p<0.05), \Delta \mathrm{C2}-7 \mathrm{SVA}(r=0.645, p<0.05)$, and $\Delta \mathrm{K}$-line tilt $(r=0.702, p<0.01)$; $\Delta$ K-line tilt was positively correlated with $\Delta$ T1s $(r=0.650, p<0.05), \Delta S A(r=0.269, p<$ $0.05)$, and $\Delta$ C2-7 SVA $(r=0.293, p<0.05)$; $\Delta$ T1s was positively correlated with $\Delta$ C2-7 lordosis $(r=0.428, p<0.05)$, $\Delta \mathrm{SA}(r=0.631, p<0.01)$, and $\Delta$ C2-7 SVA $(r=0.235, p<0.05) ; \Delta C 2-7$ lordosis was positively correlated with $\Delta S A(r$ $=0.666, p<0.05)$ and negatively correlated with $\Delta$ C2-7 SVA $(r=-0.467, p<0.01)$. The preoperative and postoperative K-line tilt values were statistically significant $(p<0.01)$, increasing from $(7.50 \pm 6.48)^{\circ}$ to $(9.95 \pm 5.09)^{\circ}$. Preoperative NDI was positively correlated with preoperative C2-7 SVA $(r=0.639, p=0.011)$ and K-line tilt $(r=$ $0.516, p=0.026)$; follow-up NDI was positively correlated with follow-up T1s $(r=0.664, p=0.038)$, C2-7 SVA ( $r=$ $0.756, p=0.004)$, and K-line tilt $(r=0.832, p=0.006)$. The linear regression model showed that when the follow-up K-lint tilt was $>23.75^{\circ}, \mathrm{NDI}$ scores were $>25\left(R^{2}=0.737, p=0.000\right)$.

Conclusion: This study showed that the K-line tilt was strongly correlated with the C2-C7 SVA, indicating that the K-line tilt can be used as another cervical parameter to evaluate cervical alignment in adjacent two-level ACDF. Kline tilt is an important parameter similar to the classical parameter C2-C7 SVA. In particular, a K-line tilt greater than 23.75 corresponded to a worse clinical prognosis, which was defined as an NDI score greater than 25.
\end{abstract}

Keywords: K-line tilt, ACDF, Cervical sagittal alignment, SVA, NDI, T1 slope

\footnotetext{
*Correspondence: 1143810401@qq.com
}

Zhibin Lan and Zhiqiang Wu are co-first authors.

${ }^{4}$ The Orthopedics Department, Fuzhou Second Hospital affiliated to Xiamen University, Fuzhou, Fujian, China

Full list of author information is available at the end of the article

C C The Author(s). 2020 Open Access This article is licensed under a Creative Commons Attribution 4.0 International License, which permits use, sharing, adaptation, distribution and reproduction in any medium or format, as long as you give appropriate credit to the original author(s) and the source, provide a link to the Creative Commons licence, and indicate if changes were made. The images or other third party material in this article are included in the article's Creative Commons licence, unless indicated otherwise in a credit line to the material. If material is not included in the article's Creative Commons licence and your intended use is not permitted by statutory regulation or exceeds the permitted use, you will need to obtain permission directly from the copyright holder. To view a copy of this licence, visit http://creativecommons.org/licenses/by/4.0/ The Creative Commons Public Domain Dedication waiver (http://creativecommons.org/publicdomain/zero/1.0/) applies to the data made available in this article, unless otherwise stated in a credit line to the data. 


\section{Background}

Many studies have indicated that the sagittal balance of the cervical spine may play an important role in clinical prognosis [1-4]. Additionally, an imbalance in the sagittal plane of the cervical spine leads to an increase in Neck Disability Index (NDI) scores [5].

Kwon et al. [6] noted that a C2-C7 sagittal vertical axis (SVA) value of $40 \mathrm{~mm}$ was the cutoff score beyond which the NDI was vastly adversely affected. Weng et al. [3] conducted a study on patients with degenerative cervical disease and found that $\mathrm{T} 1$ slope $(\mathrm{T} 1 \mathrm{~s})$, measured at the vertebral body at the intersection of the cervical spine and thoracic spine, had a significantly greater influence than the C2-7 SVA on the prognosis of patients. $\mathrm{T} 1 \mathrm{~s}$ may affect the curvature of the cervical spine to ensure that the center of gravity of the head is in a balanced position. In addition to the C2-7 SVA and T1s, other common traditional cervical sagittal plane parameters include C2-7 lordosis, segment angle (SA), neck tilt, and thoracic inlet angle.

The K-line was first described by Fujiyoshi et al. [7] as a line that connects the centers of the $\mathrm{C} 2$ and $\mathrm{C} 7$ spinal canals. This line is widely used in surgical approaches in patients with ossification of the posterior longitudinal ligament (OPLL). Fujiyoshi et al. divided cervical OPLL patients into two groups according to the position of the $\mathrm{K}$-line, including a $\mathrm{K}$-line $(+)$ group, in which the OPLL did not exceed the $\mathrm{K}$-line, and a $\mathrm{K}$-line $(-)$ group, in which the OPLL did exceed the K-line. The K-line (-) group did not exhibit satisfactory spinal cord repositioning and showed no obvious improvement in neurological function [7].

Recently, Kim et al. [8] were the first to report that Kline tilt is as important as the more traditional cervical sagittal parameter, SVA. K-line tilt is consistent with SVA, indicating a forward tilting state of the patient, in which the energy consumption of the rear muscle is increased, resulting in a poor clinical prognosis. The Pearson's correlation coefficient between the K-line tilt and C2-C7 SVA was $0.813(p=0.000)$ [8]. However, no study has verified this finding, and there has been no clinical research regarding the correction of a patient's K-line tilt. In this study, we examined the importance of K-line tilt in clinical data from patients who underwent adjacent two-level anterior cervical discectomy and fusion (ACDF) and evaluated the correlation between K-line tilt and NDI scores.

\section{Materials and methods}

\section{Patient population}

This work was approved by the institutional review board of our hospital. All methods were carried out in accordance with relevant guidelines and regulations. Informed consent was obtained from all patients (all above 18 years old). After obtaining approval from the institutional review board, the clinical and radiographic results of patients who underwent adjacent two-level ACDF of the lower cervical spine at the Department of Spine Surgery between January 2010 and December 2015 were retrospectively analyzed. All patients were diagnosed via a detailed inquiry of their medical history, a physical examination, and an imaging examination. The following inclusion criteria were applied: (1) preoperative (within 1 week before surgery), postoperative (within 3 days after surgery), and follow-up (at least 1 year after surgery) cervical X-ray films were available; (2) patients did not undergo other cervical spine surgery or cervical spine fixation; (3) signs and symptoms of spinal cord injury or nerve root damage; and (4) imaging suggested that cervical disc disease caused cervical spinal stenosis. Patients with trauma, tumor, spinal deformity, spinal infection, or severe osteoporosis were excluded. Patients in whom it was difficult to measure the sagittal alignment parameters (the T1 vertebral body could not be clearly seen on the X-ray, and the measurement of the vertebral body was blocked by the sternum or ribs on the sagittal plane) were also excluded.

\section{Radiologic parameters}

A standard cervical X-ray series was obtained and uploaded to our Picture Archiving and Communication Systems (PACS) system. To obtain a lateral radiograph, the patient was told to stand upright as far as possible and look straight ahead. The following parameters were examined (Fig. 1): (1) T1s [9]: the angle between a horizontal line and the superior endplate of $\mathrm{T} 1$; (2) $\mathrm{C} 2-7$ lordosis [1]: the angle created by a line parallel to the inferior aspect of the $\mathrm{C} 2$ body and a line parallel to that of the $\mathrm{C} 7$ body was measured on neutral lateral radiographs; (3) SA: the angle created by two lines respectively parallel to the superior and inferior aspect of the surgical segmental body was measured on neutral lateral radiographs; (4) C2-7 SVA [1]: the distance between the $\mathrm{C} 2$ plumb line and the posterior superior endplate of $\mathrm{C} 7$, with positive sagittal alignment defined as an anterior deviation; (5) K-line tilt [8]: the angle between the K-line and a line perpendicular to the horizon. The difference between preoperative and postoperative values for each parameter was designated the $\Delta$ value. NDI scores were categorized as follows: 0-20, slight dysfunction; 21-40, moderate dysfunction; 41-60, severe dysfunction; 61-80, very severe dysfunction; and 81-100, full dysfunction or requiring a detailed examination in subjects with and without exaggerated symptoms. The clinical prognosis was assessed by health-related quality of life (HRQOL) surveys, and the NDI score was obtained for each patient at the time of their preoperative (within 1 week before surgery) and last followup office visits.

\section{Statistical analysis}

SPSS 20.0 software (IBM Corp, New York, America) was used for all statistical analyses. Measurement data 


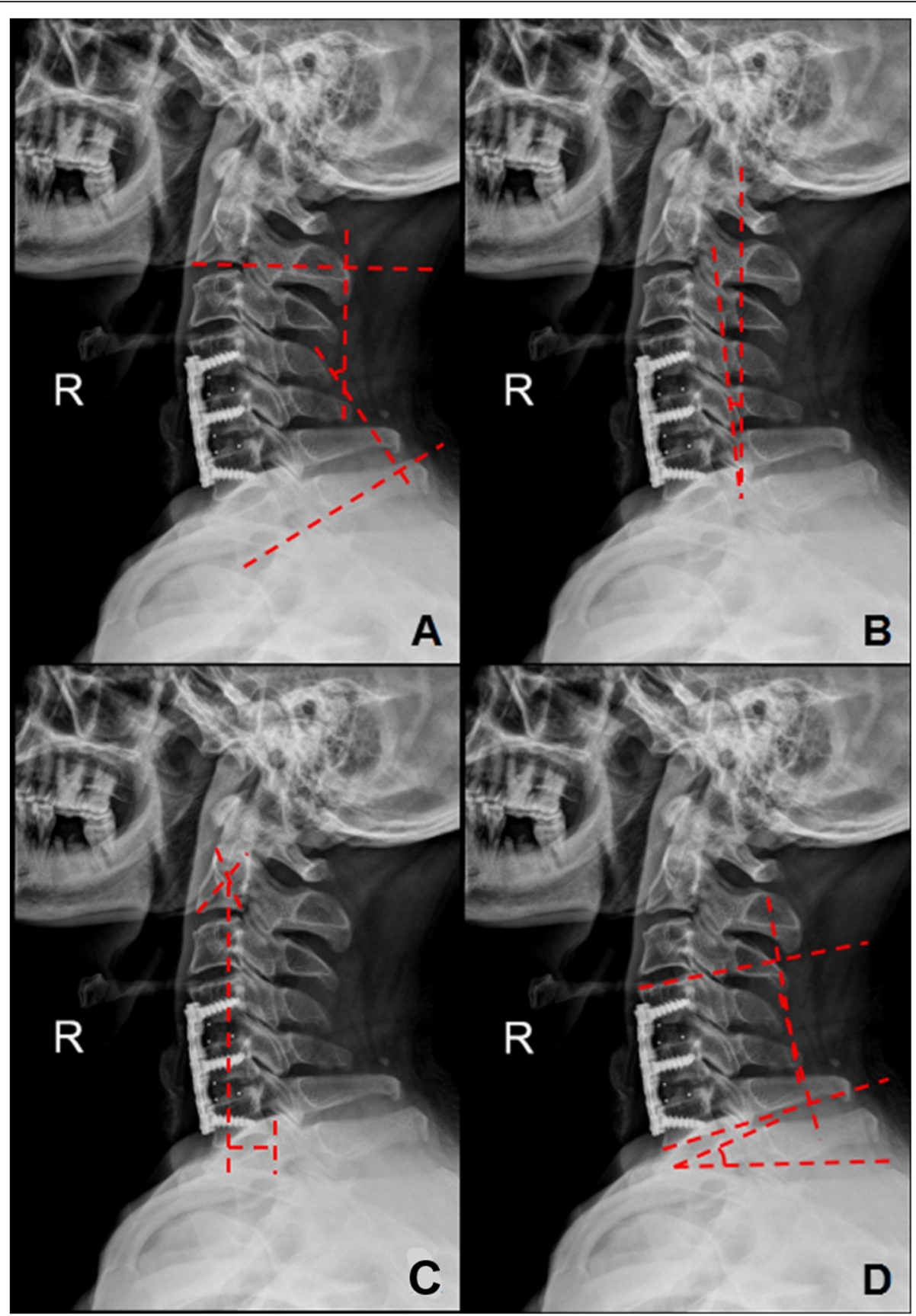

Fig. 1 Measurement of parameters. a C2-7 lordosis. b K-line tilt. c C2-7 SVA, sagittal vertical axis. d SA, segment angle; T1s, T1 slope

are shown as ${ }^{-} \mathrm{x} \pm \mathrm{s}$. The Pearson correlation coefficient was calculated for between-time-point changes in X-ray measurements. Linear regression analysis was used to analyze the relationship between sagittal parameters in the cervical spine and NDI scores. A paired $t$ test was used to evaluate the influence of the lateral position of the lower cervical spine on the sagittal position of the cervical spine. A value of $p<0.05$ was defined as statistically significant.

\section{Results}

\section{Demographic data}

Overall, we reviewed clinical data from 75 patients, 1 of whom was excluded because of traumatic injury and 2 of whom were excluded because T1 could not be measured. A total of 72 patients $(\mathrm{M} / \mathrm{F}=46 / 26)$ were included, and their mean age was $52.6 \pm 5.2$ (range, $40-68$ ) years. The following segments were involved: C3-5 (12 cases), C4-6 (39 cases), and C5-7 (21 cases). The average follow-up 
period for which postoperative radiographic measurements and HRQOL scores were obtained was $25.8 \pm 7.6$ months.

\section{Radiographic measurements and correlations}

Table 1 summarizes the preoperative and postoperative and follow-up values obtained for radiographic measurements and comparisons among them.

Pearson's correlation coefficient was calculated for changes in radiographic measures: $\triangle \mathrm{NDI}$ was positively correlated with $\Delta \mathrm{T} 1 \mathrm{~s}(r=0.620, p<0.05), \Delta \mathrm{C} 2-7 \mathrm{SVA}$ $(r=0.645, p<0.05)$ and $\Delta \mathrm{K}$-line tilt $(r=0.702, p<$ $0.01) ; \Delta \mathrm{K}$-line tilt was positively correlated with $\Delta \mathrm{T} 1 \mathrm{~s}(r$ $=0.650, p<0.05), \Delta \mathrm{SA}(r=0.269, p<0.05)$, and $\Delta \mathrm{C} 2-7$ SVA $(r=0.293, p<0.05) ; \Delta \mathrm{T} 1 \mathrm{~s}$ was positively correlated with $\Delta$ C2-7 lordosis $(r=0.428, p<0.05), \Delta$ SA $(r=$ $0.631, p<0.01)$, and $\Delta$ C2-7 SVA $(r=0.235, p<0.05)$; and $\Delta \mathrm{C} 2-7$ lordosis was positively correlated with $\Delta \mathrm{SA}$ $(r=0.666, p<0.05)$ and negatively correlated with $\Delta \mathrm{C} 2-$ 7 SVA $(r=-0.467, p<0.01)$ (Table 2).

\section{Correlations between NDI and parameters}

Comparisons between radiographic measurements and NDI scores demonstrated a significant positive correlation between K-line tilt values and NDI scores (Fig. 2).

Preoperative NDI scores were positively correlated with preoperative C2-7SVA $(r=0.639, p=0.011)$ and K-line tilt $(r=0.516, p=0.026)$, and follow-up NDI scores were positively correlated with follow-up T1s $(r=$ $0.664, p=0.038)$, C2-7 SVA $(r=0.756, p=0.004)$, and K-line tilt $(r=0.832, p=0.006)$. The linear regression model showed that when the follow-up K-line tilt was > $23.75^{\circ}$, NDI scores were $>25\left(R^{2}=0.737, p=0.000\right)$ (Table 3) (Fig. 3).

\section{Discussion}

In recent years, concern has increased regarding the importance of cervical sagittal parameters in clinical prognoses $[1,4,5]$. Therefore, accurately and rapidly evaluating cervical sagittal balance requires good cervical parameters.

We found that T1s, C2-7 lordosis and C2-7 SVA were the three most important sagittal parameters in the cervical spine. A study by Kim et al. [4] showed that patients with a large T1s required increased cervical lordosis and increased energy consumption in the upper cervical spine to maintain their head weight. A study by Oe et al. [10] showed that when $\mathrm{T} 1 \mathrm{~s}>40^{\circ}$, the probability of failure was higher for deformity corrections performed in the cervical vertebra. Many studies have also noted that maintaining surgical intervention for $\mathrm{C} 2-7$ lordosis has a positive effect on a patient's prognosis, perhaps because less energy is consumed by the neck muscles and ligaments [11-13]. Tang et al. [5] also suggested that when C2-7 SVA $>40$ $\mathrm{mm}$, NDI scores will be worse.

In this study, from Table 1, we could conclude that the surgery mainly changed the SA $(p=0.000)$ and Kline tilt $(p=0.000)$, but by analyzing the correlations among $\Delta$ values (Table 2), we concluded that surgery indirectly changed other sagittal parameters by directly changing the SA and K-line tilt. These data clearly indicated that ACDF surgery maintains global lordosis mainly by increasing regional lordosis.

Among the indicators measured, the correlation between C2-7 lordosis and NDI scores was not obviously significant. The T1 vertebral body is not a direct surgical segment because it cannot be directly changed by surgery but must instead be indirectly changed. These changes were relatively small. The good cervical sagittal observation index can evaluate the curvature of the entire cervical vertebrae. As the most active cervical vertebra, it is impossible to display the complete cervical vertebrae by simply evaluating $\mathrm{T} 1 \mathrm{~s}$, but the K-line tilt (a line connecting the centers of the $\mathrm{C} 2$ and $\mathrm{C} 7$ spinal canals) can better evaluate sagittal balance. Furthermore, the T1s is not easy to measure because the thoracic spine is difficult to correctly identify on a simple lateral X-ray film due to anatomical interference from the shoulder contour density, especially in obese people with thick thoraces [14]. Although T1s minus C2-7 lordosis (T1s-CL) is also a good cervical parameter, it is more difficult to measure and use. The K-line can be measured by identifying and connecting the two midpoints of the $\mathrm{C} 2$ and $\mathrm{C} 7$ spinal canals. Therefore, K-line tilt detection is simple and convenient and can be performed quickly and intuitively.

Of the indicators evaluated in our study, we found that both K-line tilt and C2-7 SVA were substantially correlated

Table 1 Effects on cervical sagittal alignment parameters following adjacent two-level ACDF

\begin{tabular}{|c|c|c|c|c|c|}
\hline Item & Preoperative & Postoperative & Follow-up & $p$ value & $p^{*}$ value \\
\hline $\mathrm{T} 1 \mathrm{~s}\left({ }^{\circ}\right)$ & $27.78 \pm 8.70$ & $28.24 \pm 6.67$ & $27.61 \pm 9.71$ & 0.573 & 0.841 \\
\hline C2-7 lordosis $\left(^{\circ}\right)$ & $17.80 \pm 9.72$ & $18.62 \pm 6.84$ & $17.42 \pm 8.42$ & 0.430 & 0.723 \\
\hline $\mathrm{SA}\left({ }^{\circ}\right)$ & $3.62 \pm 9.14$ & $9.68 \pm 4.28$ & $7.73 \pm 4.90$ & 0.000 & 0.000 \\
\hline C2-7 SVA $(\mathrm{cm})$ & $2.40 \pm 1.86$ & $2.65 \pm 1.12$ & $2.43 \pm 1.64$ & 0.236 & 0.918 \\
\hline K-line tilt $\left(^{\circ}\right)$ & $7.50 \pm 6.48$ & $9.95 \pm 5.09$ & $9.49 \pm 8.95$ & 0.000 & 0.001 \\
\hline
\end{tabular}

$p$ value comparison between preoperative and postoperative, $p^{*}$ value comparison between preoperative and follow-up, T1s T1 slope, SA segmental angle, C27SVA sagittal vertical axis 
Table 2 Correlations between the changes of sagittal alignment parameters following adjacent two-level ACDF

\begin{tabular}{|c|c|c|c|c|c|c|c|}
\hline & & $\Delta \mathrm{T} 1 \mathrm{~s}$ & $\Delta C 2-7$ lordosis & $\Delta \mathrm{SA}$ & $\Delta C 2-7$ SVA & $\Delta \mathrm{K}$-line tilt & $\Delta \mathrm{NDI}$ \\
\hline \multirow[t]{2}{*}{$\overline{\Delta \mathrm{T} 1 \mathrm{~s}}$} & $r$ & 1 & $.428^{*}$ & $.631^{* *}$ & $.235^{*}$ & $.650^{*}$ & $.620^{*}$ \\
\hline & $p$ & & .037 & .005 & .047 & .042 & .086 \\
\hline \multirow[t]{2}{*}{$\Delta \mathrm{C} 2-7$ lordosis } & $r$ & $.428^{*}$ & 1 & $.666^{*}$ & $-.467^{* *}$ & -.023 & .102 \\
\hline & $p$ & .037 & & .022 & .009 & .847 & .382 \\
\hline \multirow[t]{2}{*}{$\Delta S A$} & r & $.631^{* *}$ & $.666^{*}$ & 1 & -.121 & $.269^{*}$ & -.080 \\
\hline & $p$ & .005 & .022 & & .312 & .026 & .592 \\
\hline \multirow[t]{2}{*}{$\Delta C 2-7 S V A$} & $r$ & $.235^{*}$ & $-.467^{* *}$ & -.121 & 1 & $.293^{*}$ & $.645^{*}$ \\
\hline & $p$ & .047 & .009 & .312 & & .013 & .048 \\
\hline \multirow[t]{2}{*}{$\Delta \mathrm{K}$-line tilt } & r & $.650^{*}$ & -.023 & $.269^{*}$ & $.293^{*}$ & 1 & $.702^{* *}$ \\
\hline & $p$ & .042 & .847 & .026 & .013 & & .028 \\
\hline \multirow[t]{2}{*}{$\Delta N D I$} & r & $.620^{*}$ & .102 & -.080 & $.645^{*}$ & $.702^{* *}$ & 1 \\
\hline & $p$ & .086 & .382 & .592 & .048 & .028 & \\
\hline
\end{tabular}

T1s T1 slope, SVA sagittal vertical axis, SA segmental angle, NDI neck disability index

${ }^{*}$ Correlation is significant at the $p<0.05$ level (2-tailed)

${ }^{* *}$ Correlation is significant at the $p<0.01$ level (2-tailed)

with NDI scores ( $r=0.832$ vs 0.756$)$, and K-line tilt was positively correlated with C2-7 SVA $(r=0.707, p=0.008)$ and T1s $(r=0.501, p=0.036)$. During the operation, the angle is more intuitive than the length because there is no need to consider the effect of scale. Therefore, we believe that K-line tilt may provide a more advantageous assessment method. Linear regression analysis was used to analyze the relationship between K-line tilt and NDI scores, and the results indicated that when the follow-up K-line tilt was $>23.75^{\circ}$, the NDI scores were $>25\left(R^{2}=0.737, p=\right.$ $0.000)$. In this regard, we believe that if the patient's K-line tilt is larger before surgery, it may be considered to increase the size of the cage $(5,6$, and $7 \mathrm{~mm}$ are commonly used) during surgery and to correct the regional lordosis, which will yield a better prognosis for the patient.

This study only included a small number of sample statistics. Moreover, this study was retrospective, and therefore, some unintended biases could exist, such as selection bias and information bias. NDI scores were used to evaluate the clinical prognosis and as a quality of life index, and the JOA scores, SF-36, and VAS scores were not measured. We chose adjacent two-level ACDF because the single-segment surgery (single-segment ACCF or disc replacement, etc.) resulted in little change in sagittal parameters before and after

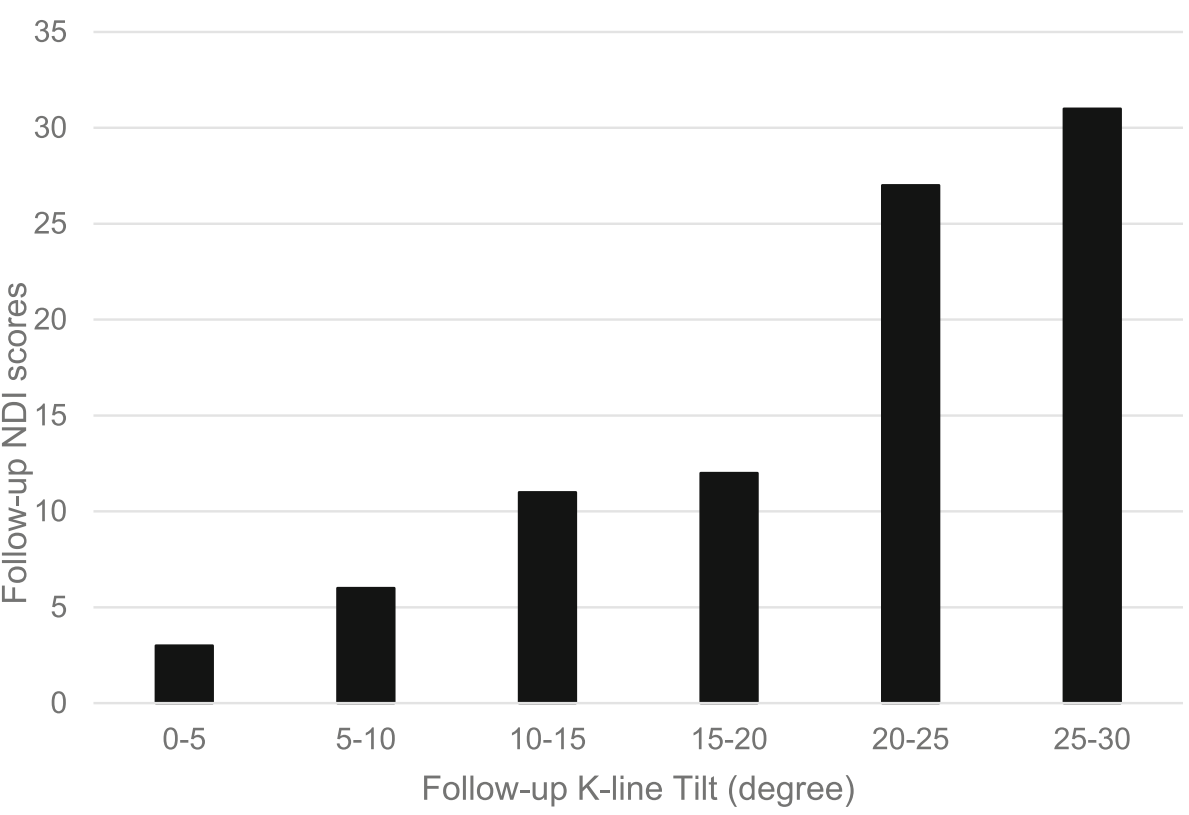

Fig. 2 Bar graph of mean data showing a positive correlation between follow-up K-line tilt and NDI scores. NDI, neck disability index 
Table 3 Correlations between sagittal parameters and NDI scores

\begin{tabular}{llll}
\hline & Sagittal parameters & Correlation (Spearman r) & $p$ value \\
\hline Preoperative NDI scores & Preoperative T1s & 0.652 & 0.072 \\
& Preoperative C2-7 lordosis & 0.090 & 0.451 \\
& Preoperative SA & -0.078 & 0.517 \\
& Preoperative C2-7 SVA & $0.639^{*}$ & 0.011 \\
& Preoperative K-line tilt & $0.516^{*}$ & 0.026 \\
Follow-up NDI scores & Follow-up T1s & $0.664^{*}$ & 0.117 \\
& Follow-up C2-7 lordosis & -0.065 & 0.326 \\
& Follow-up SA & $0.756^{* *}$ & 0.585 \\
& Follow-up C2-7 SVA & $0.032^{* *}$ & 0.004
\end{tabular}

NDI neck disability index, T1s T1 slope, SA segment angle, SVA sagittal vertical axis

*Correlation is significant at the $p<0.05$ level (2-tailed)

${ }^{* *}$ Correlation is significant at the $p<0.01$ level (2-tailed)

surgery. There were more patients with two-level ACDF in our hospital. In principle, if there are sufficient segments to perform multi-segment ACDF, this approach is best. In this study, we only had one experienced doctor to measure the data, which inevitably leads to errors. We hope that a follow-up study will enhance and verify the value of this article by increasing the sample size and improving scoring standards.

\section{Conclusion}

This study showed that the K-line tilt was strongly correlated with the $\mathrm{C} 2-\mathrm{C} 7 \mathrm{SVA}$, indicating that the $\mathrm{K}$-line

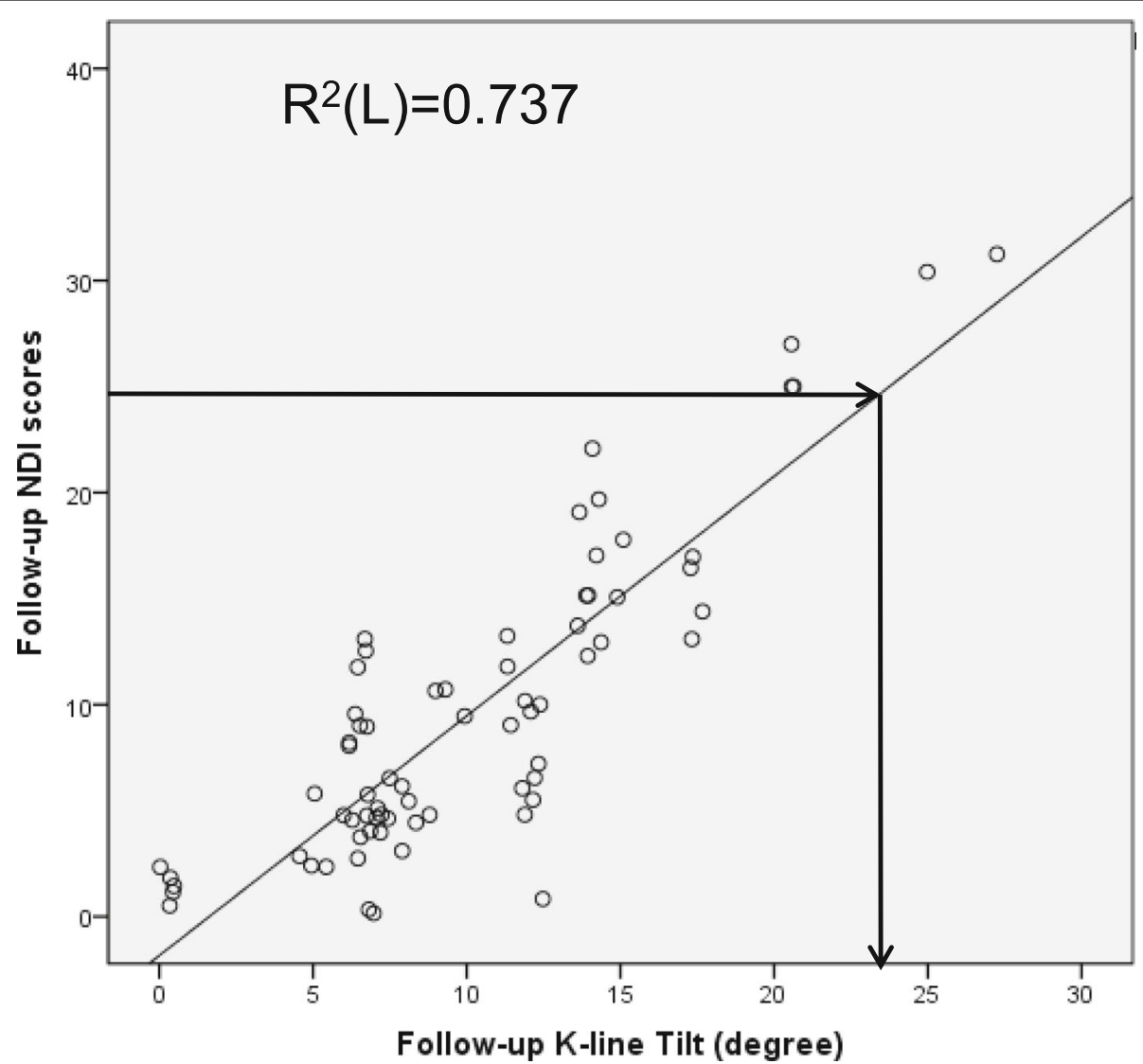

Fig. 3 The linear regression model of follow-up K-line tilt and NDI scores showed that when K-line tilt was $>23.75^{\circ}$. NDI scores were $>25$ $\left(R^{2}=0.737, p=0.000\right)$. NDI, neck disability index 
tilt could be used as another cervical parameter to evaluate cervical alignment in adjacent two-level ACDF. The K-line tilt was also an important parameter, similar to the classical parameter C2-C7 SVA. In particular, a K-line tilt greater than 23.75 corresponded to a worse clinical prognosis, which was defined as an NDI score greater than 25 .

\section{Abbreviations}

ACDF: Anterior cervical discectomy and fusion; HRQOL: Health-related quality of life; NDI: Neck disability index; SA: Segment angle; SVA: Sagittal vertical axis; T1s: T1 slope

\section{Acknowledgements}

We are grateful to all study participants for their participation in the study.

\section{Authors' contributions}

Zhibin Lan and Weihong Xu were responsible for patient selection and recruitment and drafting of the manuscript. Weihong Xu was responsible for measuring the radiological parameters. Yuming Huang and Zhiqiang Wu were responsible for designing the study, carrying out the surgical procedures, and critically revising the manuscript. Zhiqiang Wu was responsible for statistical analysis. The authors read and approved the final manuscript.

\section{Funding}

There is no funding for the current study.

\section{Availability of data and materials}

To preserve the privacy of the patients, their clinical data will not be shared; data can be available from authors upon request.

\section{Ethics approval and consent to participate}

The study was approved by the ethics committee of The First Affiliated Hospital of Fujian Medical University. All patients gave written consent for research applications of their clinical data. The patient data were anonymized in this study.

\section{Consent for publication}

Not applicable.

\section{Competing interests}

The authors declare that they have no competing interests.

\begin{abstract}
Author details
${ }^{1}$ Spinal Surgery Department, The First Affiliated Hospital of Fujian Medical University, Quanzhou Orthopedic-Traumatological Hospital of Fujian Traditional Chinese Medicine University, Fuzhou, Fujian, China. ${ }^{2}$ Spinal Surgery Department, Quanzhou Orthopedic-Traumatological Hospital of Fujian Traditional Chinese Medicine University, Quanzhou, Fujian, China. ${ }^{3}$ Department of Spine Surgery, The First Affiliated Hospital of Fujian Medical University, Fuzhou, Fujian, China. ${ }^{4}$ The Orthopedics Department, Fuzhou Second Hospital affiliated to Xiamen University, Fuzhou, Fujian, China.
\end{abstract}

Received: 28 November 2019 Accepted: 19 March 2020

Published online: 07 April 2020

\section{References}

1. Hyun SJ, Kim KJ, Jahng TA, Kim HJ. Relationship between T1 slope and cervical alignment following multilevel posterior cervical fusion surgery: impact of T1 slope minus cervical lordosis. Spine (Phila Pa 1976). 2016;41: E396-402.

2. Steinmetz MP, Stewart TJ, Kager CD, Benzel EC, Vaccaro AR. Cervical deformity correction. Neurosurgery. 2007;60:S90-7.

3. Weng C, Wang J, Tuchman A, Wang J, Fu C, Hsieh PC, et al. Influence of T1 slope on the cervical sagittal balance in degenerative cervical spine: an analysis using kinematic MRI. Spine (Phila Pa 1976). 2016;41:185-90.
4. Kim TH, Lee SY, Kim YC, Park MS, Kim SW. T1 slope as a predictor of kyphotic alignment change after laminoplasty in patients with cervical myelopathy. Spine (Phila Pa 1976). 2013;38:E992-7.

5. Tang JA, Scheer JK, Smith JS, Deviren V, Bess S, Hart RA, et al. The impact of standing regional cervical sagittal alignment on outcomes in posterior cervical fusion surgery. Neurosurgery. 2015;76(Suppl 1):S14-21 discussion S21.

6. Kwon WK, Kim PS, Ahn SY, Song JY, Kim JH, Park YK, et al. Analysis of associating factors with C2-7 sagittal vertical axis after two-level anterior cervical fusion: comparison between plate augmentation and stand-alone cages. Spine (Phila Pa 1976). 2017:42:318-25.

7. Fujiyoshi T, Yamazaki M, Kawabe J, Endo T, Furuya T, Koda M, et al. A new concept for making decisions regarding the surgical approach for cervical ossification of the posterior longitudinal ligament: the K-line. Spine (Phila Pa 1976). 2008:33:E990-3.

8. Kim HS, Kim TH, Park MS, Kim SW, Chang HG, Kim JH, et al. K-line tilt as a novel radiographic parameter in cervical sagittal alignment. Eur Spine J. 2018;27:2023-8

9. Lee SH, Kim KT, Seo EM, Suk KS, Kwack YH, Son ES. The influence of thoracic inlet alignment on the craniocervical sagittal balance in asymptomatic adults. J Spinal Disord Tech. 2012;25:E41-7.

10. Oe S, Yamato Y, Togawa D, Kurosu K, Mihara Y, Banno T, et al. Preoperative $\mathrm{T} 1$ slope more than $40^{\circ}$ as a risk factor of correction loss in patients with adult spinal deformity. Spine (Phila Pa 1976). 2016;41:E1168-76.

11. Jenkins LA, Capen DA, Zigler JE, Nelson RW, Nagelberg S. Cervical spine fusions for trauma. A long-term radiographic and clinical evaluation. Orthop Rev. 1994;(Suppl):13-9.

12. Kawakami M, Tamaki T, Yoshida M, Hayashi N, Ando M, Yamada H. Axial symptoms and cervical alignments after cervical anterior spinal fusion for patients with cervical myelopathy. J Spinal Disord. 1999;12:50-6.

13. Park MS, Kelly MP, Lee DH, Min WK, Rahman RK, Riew KD. Sagittal alignment as a predictor of clinical adjacent segment pathology requiring surgery after anterior cervical arthrodesis. Spine J. 2014;14:1228-34.

14. Jun HS, Chang IB, Song JH, Kim TH, Park MS, Kim SW, et al. Is it possible to evaluate the parameters of cervical sagittal alignment on cervical computed tomographic scans. Spine (Phila Pa 1976). 2014;39:E630-6.

\section{Publisher's Note}

Springer Nature remains neutral with regard to jurisdictional claims in published maps and institutional affiliations.

\section{Ready to submit your research? Choose BMC and benefit from:}

- fast, convenient online submission

- thorough peer review by experienced researchers in your field

- rapid publication on acceptance

- support for research data, including large and complex data types

- gold Open Access which fosters wider collaboration and increased citations

- maximum visibility for your research: over $100 \mathrm{M}$ website views per year

At BMC, research is always in progress.

Learn more biomedcentral.com/submissions 